\title{
Relationship of chest CT score with clinical characteristics of 108 patients hospitalized with COVID-19 in Wuhan, China
}

Jie Zhang ${ }^{1 \dagger}$, Guangping Meng ${ }^{1 \dagger}$, Wei $\mathrm{Li}^{1 \dagger}$, Bingqing Shi ${ }^{1}$, Hongna Dong ${ }^{1}$, Zhenzhong Su${ }^{1}$, Qian Huang ${ }^{2}$ and Peng Gao ${ }^{1 *}$ (D)

\begin{abstract}
Background: In December 2019, the outbreak of a disease subsequently termed COVID-19 occurred in Wuhan, China. The number of cases increased rapidly and spread to six continents. However, there is limited information on the chest computed tomography (CT) results of affected patients. Chest CT can assess the severity of COVID-19 and has sufficient sensitivity to assess changes in response to glucocorticoid therapy.

Objective: Analyze COVID-19 patients to determine the relationships of clinical characteristics, chest CT score, and levels of inflammatory mediators.

Methods: This retrospective, single-center case series of 108 consecutive hospitalized patients with confirmed COVID-19 at Tongji Hospital, Tongji Medical College of HUST (Wuhan, China) examined patients admitted from January 28 to February 20, 2020. Patient demographics, comorbidities, clinical findings, chest CT results, and CT scores of affected lung parenchyma were recorded. The relationships between chest $C T$ score with levels of systemic inflammatory mediators were determined.

Results: All patients exhibited signs of significant systemic inflammation, including increased levels of C-reactive protein (CRP), erythrocyte sedimentation rate (ESR), procalcitonin, chest CT score, and a decreased lymphocyte (LY) count. Chest CT score had positive associations with white blood cell (WBC) count, CRP, ESR, procalcitonin, and abnormal coagulation function, and a negative association with LY count. Treatment with a glucocorticoid increased the LY count, reduced the CT score and CRP level, and improved coagulation function.
\end{abstract}

Conclusions: COVID-19 infection is characterized by a systemic inflammatory response that affects the lungs, blood, digestive system, and circulatory systems. The chest CT score is a good indicator of the extent of systemic inflammation. Glucocorticoid treatment appears to reduce systemic inflammation in these patients.

Keywords: COVID-19, Chest CT score, Inflammation, Glucocorticoid, Treatment

\footnotetext{
* Correspondence: gaopeng1234@sina.com

†Jie Zhang, Guangping Meng and Wei Li contributed equally to this work.

'Department of Respiratory and Critical Care Medicine, The Second Hospital of Jilin University, Changchun, Jilin, China

Full list of author information is available at the end of the article
}

(C) The Author(s). 2020 Open Access This article is licensed under a Creative Commons Attribution 4.0 International License, which permits use, sharing, adaptation, distribution and reproduction in any medium or format, as long as you give appropriate credit to the original author(s) and the source, provide a link to the Creative Commons licence, and indicate if changes were made. The images or other third party material in this article are included in the article's Creative Commons licence, unless indicated otherwise in a credit line to the material. If material is not included in the article's Creative Commons licence and your intended use is not permitted by statutory regulation or exceeds the permitted use, you will need to obtain permission directly from the copyright holder. To view a copy of this licence, visit http://creativecommons.org/licenses/by/4.0/ The Creative Commons Public Domain Dedication waiver (http://creativecommons.org/publicdomain/zero/1.0/) applies to the data made available in this article, unless otherwise stated in a credit line to the data. 


\section{Background}

On Dec 8, 2019, there were reports of several cases of pneumonia of unknown etiology in Wuhan (Hubei Province, China). The disease (now termed COVID-19) spread rapidly from Wuhan to other areas. As of March 15,2020 , there were 80,860 confirmed cases in China, 72,469 cases in 143 other countries, and cases in 6 continents [1-5]. On January 3, 2020, this novel coronavirus (now termed SARS-CoV-2) was identified in samples of bronchoalveolar lavage fluid from a patient in Wuhan and confirmed as the cause of this disease [6]. During the early stages of this pneumonia, there were severe acute respiratory symptoms (SARS), and some patients rapidly developed acute respiratory distress syndrome (ARDS), acute respiratory failure, and other serious complications [7]. On Jan 7, the Chinese Center for Disease Control and Prevention (CDC) identified this novel coronavirus from the throat swab of a patient [8]. Other coronaviruses cause multiple system infections in various animals, and mainly respiratory tract infections in humans, such as severe acute respiratory syndrome (SARS) and Middle East respiratory syndrome (MERS) $[9,10]$. Most patients infected by SARS-CoV-2 have mild symptoms and good prognosis. However, some patients with COVID-19 progressed from severe pneumonia to pulmonary edema, acute respiratory distress syndrome, multiple organ failure, and death [11, 12].

A confirmed diagnosis of COVID-19 infection requires PCR identification of viral nucleic acid and lung imaging [13]. Most patients have lung imaging results indicating bilateral pulmonary parenchymal ground-glass and consolidative pulmonary opacities, sometimes with a rounded morphology and peripheral lung distribution. Notably, lung cavitation, discrete pulmonary nodules, pleural effusions, and lymphadenopathy are absent [13].

At present, there is little known about the relationship between imaging results indicative of pneumonia and the presence of systemic inflammatory mediators in patients with COVID-19. The purpose of this study is to evaluate the severity of COVID-19 infection by quantifying chest $\mathrm{CT}$ results and to determine the relationship between chest $\mathrm{CT}$ scores and systemic inflammatory mediators in an effort to identify factors that can be used against the COVID-19 pandemic.

\section{Methods}

Study design and participants

Ethical approval was received from the Ethics Committee of the Second Hospital of Jilin University.

A total of 108 patients with COVID-19 were enrolled in the Department of Respiratory and Critical Care Medicine of the Tongji Hospital Sino-French New Town, Tongji Medical College of HUST between January 28 and February 20, 2020. Oral consent was obtained from patients. All patients with COVID-19 were diagnosed using a PCR test and all patients met the requirements of Wuhan Health and Medical Commission for admission, all patients were general or severe according to the fourth edition of the treatment plan [14].

\section{Chest CT imaging}

Chest CT scores were the average of scores (range: 0 to 10) assigned by two independent radiologists, each with more than 5 years of experience in chest $\mathrm{CT}$ diagnosis. If the assigned scores differed by more than 1 , then a senior radiologist, with more than 10 years of experience, arbitrated so that the final assigned scores differed by 1 or less.

According to convention, the lung was divided into five levels, from the apex to the bottom: suprasternal notch, aortic arch, the tracheal carina, intermediate bronchus, and apex of diaphragm (Additional Figure $1 \mathrm{~A}-\mathrm{E})$. The left and right lungs were scored separately, and each of the 5 lung zones in each patient was assigned a score according to distribution of affected parenchyma as previously described [15] (0, normal; 1 , $10 \%$ abnormality; 2, 20\% abnormality; etc.). The chest CT density was also graded (0, normal attenuation; 1 , frosted glass density; 2, ground-glass attenuation; and 3, consolidation; Fig. 1). Then the lung parenchyma score was then multiplied by the square of the CT density

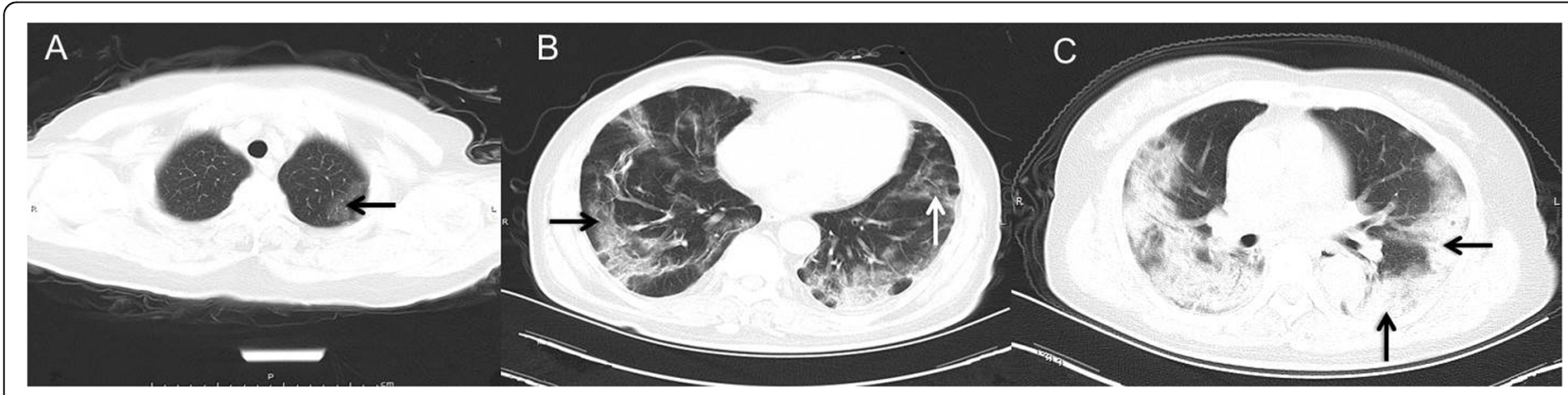

Fig. 1 Representative lung CT images of patients who had frosted glass density (a), ground glass opacity (b), and consolidation (c) 
score and points from all zones and added for a final total cumulative score that ranged from 0 to 900 .

\section{Data collection}

Demographic and clinical data were collected, including age, gender, medical history, smoking status, results from a physical examination, laboratory results, and chest CT results. Patients were divided into three subgroups based on chest CT score. The date of disease onset was defined as the day when symptoms were first noticed.

The validity of all data were checked by two physicians (BS and HD).

\section{Statistical analysis}

IBM SPSS Statistics 20.0 was used for data analysis. Data with normal distributions are presented as the means \pm standard deviations (SDs) and analyzed by Student's ttest, ANOVA, and a post hoc least significant difference (LSD) tests. Non-parametric data are expressed as medians and interquartile ranges (IQRs) and analyzed by the Kruskal-Wallis test with the Bonferroni correction or the Mann-Whitney U test. Correlations were determined using Spearman's rank correlation coefficient. Categorical variables were analyzed using a Chi-square test. A $P$-value below 0.05 was defined as significant.

\section{Results}

\section{Presenting characteristics}

The study population consisted of 108 hospitalized patients with confirmed COVID-19 (Table 1). There were 25 patients (23\%) under 50 years-old, $83(77 \%)$ over 50 years-old, the median age was 66 years (interquartile range [IQR]: 51 to 72 ; range: 23 to 86 ), and 60 patients (55.6\%) were men. The median duration from initial symptoms to dyspnea was 5 days (IQR: 0 to 7 ) and from first symptoms to admission was 10 days (IQR: 6 to 15). Forty-eight patients (44\%) had an underlying disease, and the most common underlying diseases were hypertension $(n=44,40.7 \%)$, diabetes $(n=18,16.7 \%)$, and cardiovascular disease $(n=16,14.8 \%)$. The most common symptoms at the onset of illness were fever $(n=93$, $86 \%)$, cough $(n=78,72.2 \%)$, and sputum production ( $n=44,40.7 \%$ ), followed by diarrhea, fatigue, abdominal pain, headache, and vomiting. Sixty-five patients (60.2\%) had dyspnea. In addition, one patient changed from severely ill to critically ill, and received endotracheal intubation and extracorporeal membrane oxygenation (ECMO), but eventually died (mortality rate: $1 / 108$, $0.93 \%)$.

\section{Laboratory parameters}

The white blood cell counts of patients on admission were above the reference range in 10 patients (9.3\%) and
Table 1 Demographic and baseline characteristics of patients $(n=108)$

\begin{tabular}{ll}
\hline Variable & Median (IQR) or n (\%) \\
\hline Age, years & \\
Median & $66(51,72)$ \\
Range & 23,86 \\
$<50$ & $25(23 \%)$ \\
$\geq 50$ & $83(77 \%)$ \\
Sex (male) & $60(55.6 \%)$ \\
Current smoking & $11(10.2 \%)$ \\
Comorbidities & \\
Hypertension & $44(40.7 \%)$ \\
Cardiovascular disease & $16(14.8 \%)$ \\
Diabetes & $18(16.7 \%)$ \\
Malignancy & $4(3.7 \%)$ \\
Cerebrovascular disease & $3(3.7 \%)$ \\
COPD & $5(4.6 \%)$ \\
Chronic kidney disease & $3(2.8 \%)$ \\
Chronic liver disease & $5(4.6 \%)$ \\
Signs and symptoms & \\
Fever & $20(20,21)$ \\
Dry cough & $132(121,141)$ \\
Sputum production &
\end{tabular}

Data are indicated as $\mathrm{n}(\%), \mathrm{n} / \mathrm{N}(\%)$

below the reference range in 10 patients (Table 2). Fiftysix patients (52\%) had decreased LY counts, 62 patients (57\%) patients had elevated D-dimer levels, 30 patients (28\%) had elevated serum creatinine levels, 46 patients (43\%) had elevated creatine kinase-MB (CK-MB) levels, 33 patients (31\%) patients had increased procalcitonin levels, 87 patients $(81 \%)$ had elevated CRP levels, and 76 patients $(70 \%)$ had elevated levels of ESR. 
Table 2 Laboratory findings of patients upon admission

\begin{tabular}{|c|c|c|c|c|c|}
\hline \multirow[t]{3}{*}{ Variable } & \multicolumn{4}{|l|}{ Patients } & \multirow[t]{3}{*}{$P$ value } \\
\hline & & \multicolumn{3}{|c|}{ Chest $C T$ score subgroup } & \\
\hline & & 0-100(group 1) & 101-200(group 2) & $>200$ (group 3) & \\
\hline $\mathrm{N}$ & 108 & 50 & 23 & 11 & \\
\hline \multicolumn{6}{|l|}{ Blood cells } \\
\hline WBCs $\times 10^{9} / \mathrm{L}$, normal range: $3.5-9.5$ & $5.7(4.5,7.8)$ & $5.9(4.4,7.8)^{\triangleleft}$ & $5.5(4.6,6.1)^{\Delta}$ & $5.4(4.4,9.5))^{* \S}$ & 0.001 \\
\hline Increased & $10(9.3 \%)$ & $6(12 \%)$ & $0(0 \%)$ & $2(18 \%)$ & / \\
\hline Decreased & $10(9.3 \%)$ & $5(10 \%)$ & $2(9 \%)$ & $1(9 \%)$ & / \\
\hline Neutrophils $\times 10^{9} / \mathrm{L}$, normal range: $1.8-6.3$ & $4.1(2.9,5.9)$ & $4.4(2.7,6.1)^{\Delta}$ & $3.5(3.1,4.3)^{\Delta}$ & $3.8(2.9,7.4)^{* \S}$ & $<0.001$ \\
\hline LYs $\times 10^{9} / \mathrm{L}$, normal range: $1.1-3.2$ & $1.1(0.75,1.55)$ & $1.1(0.77,1.51)^{\S \Delta}$ & $1.15(0.67,1.73)^{*}$ & $0.83(0.74,1.27)^{*}$ & $<0.001$ \\
\hline Decreased & $56(52 \%)$ & $26(52 \%)$ & $11(48 \%)$ & $7(64 \%)$ & / \\
\hline Platelets $\times 10^{9} / \mathrm{L}$, normal range: $125-350$ & $266(174,340)$ & $265(156,338)$ & $268(160,363)$ & $261(211,342)$ & 0.251 \\
\hline Haemoglobin, g/L, normal range: 115-150 & $129(114,143)$ & $130(111,144)$ & $129(117,136)$ & $127(114,147)$ & 0.410 \\
\hline \multicolumn{6}{|l|}{ Coagulation parameters } \\
\hline Activated partial thromboplastin time, s, normal range: $29-42$ & $38.3(35.8,41.2)$ & $38.2(35.7,40.7)$ & $38.5(36.1,41.9)$ & $41.3(36.1,44)$ & 0.909 \\
\hline Prothrombin time, s, normal range: $11.5-14.5$ & $13.8(13.3,14.3)$ & $13.9(13.6,14.5)$ & $13.7(13.2,14.6)$ & $13.6(13,14.3)$ & 0.076 \\
\hline D-dimer, $\mu \mathrm{g} / \mathrm{mL}$, normal range: $<0.5$ & $0.71(0.40,1.58)$ & $0.64(0.31,1.67)^{\& \Delta}$ & $0.58(0.42,1.2) \nabla$ & $0.84(0.46,1.83)^{*}$ & $<0.001$ \\
\hline Increased & $62(57 \%)$ & $20(40 \%)$ & $11(48 \%)$ & $5(46 \%)$ & / \\
\hline \multicolumn{6}{|l|}{ Blood biochemistry } \\
\hline Albumin, g/L, normal range: $35-52$ & $35.3(32,39.4)$ & $36.3(31.8,40)$ & $37.2(32.4,40.2)$ & $33.3(31,37.7)$ & 0.183 \\
\hline Alanine aminotransferase, $U / L$, normal range: $\leq 33$ & $27(17,43)$ & $29(16.8,45)$ & $31(18,48)$ & $21(15,32)$ & 0.426 \\
\hline Aspartate aminotransferase, $\mathrm{U} / \mathrm{L}$, normal range: $\leq 32$ & $25(21,39)$ & $24(21,37)$ & $32(23,47)$ & $25(19,38)$ & 0.778 \\
\hline Total bilirubin, mmol/L, normal range: $\leq 21$ & $9.5(7.2,13)$ & $8.9(6.9,12.1)$ & $11.6(7.9,15.1)$ & $9.8(7.1 ., 13.4)$ & 0.068 \\
\hline Blood urea nitrogen, $\mathrm{mmol} / \mathrm{L}$, normal range: $1.7-8.3$ & $4.8(3.6,6.1)$ & $5(3.6,6)^{8)}$ & $4.7(3.7,5.3) \boldsymbol{\nabla}$ & $4.7(3.6,7) \boldsymbol{\nabla}$ & 0.022 \\
\hline Serum creatinine, $\mu \mathrm{mol} / \mathrm{L}$, normal range: $45-84$ & $71(57,86)$ & $70(57,86)$ & $81(67,87)$ & $68(55,78)$ & 0.538 \\
\hline Increased & $30(28 \%)$ & $14(28 \%)$ & $10(44 \%)$ & $1(9 \%)$ & / \\
\hline CK-MB, ng/mL, normal range: $\leq 7.2$ & $65.5(14,123)$ & $72(25,110)$ & $56(3116)$ & $101(15,182)$ & 0.493 \\
\hline Increased & $46(43 \%)$ & $23(46 \%)$ & $6(26 \%)$ & $6(55 \%)$ & / \\
\hline Lactate dehydrogenase, U/L, normal range: 135-214 & $262(228,333)$ & $261(226,325)^{\S \Delta}$ & $267(236,340)^{* \Delta}$ & $264(225,328)^{* 5}$ & $<0.001$ \\
\hline Troponin, pg/mL, normal range: $\leq 15.6$ & $4.5(1.9,10)$ & $3.6(1.9,5.9)^{\Delta}$ & $6.7(2.6,12.3)^{\prime}$ & $5.2(3.4,15.7) *$ & 0.013 \\
\hline Myoglobin, ng/mL, normal range: $\leq 154.9$ & $59(41,113)$ & $49(40,72)$ & $74(36,127)$ & $59(24,132)$ & 0.072 \\
\hline Glucose, mmol/L, normal range: $4.11-6.05$ & $6.3(5.6,8.3)$ & $6.1(5.4,8.2)$ & $7.4(5.7,11.7)$ & $7.9(6.4,9.7)$ & 0.108 \\
\hline \multicolumn{6}{|l|}{ Infection-related biomarkers } \\
\hline Procalcitonin, ng/mL, normal range: $0.02-0.05$ & $0.04(0.02,0.07)$ & $0.03(0.02,0.05)^{\S \Delta}$ & $0.07(0.04,0.16)^{*}$ & $0.07(0.04,0.19)^{*}$ & $<0.001$ \\
\hline Increased & $33(31 \%)$ & $8(16 \%)$ & $13(57 \%)$ & $7(64 \%)$ & / \\
\hline ESR, s, normal range: $0-20$ & $40(20,66)$ & $36(18,54)^{5}$ & $68(35,84)^{*}$ & $58(42,68)$ & 0.002 \\
\hline Increased & $76(70 \%)$ & $36(72 \%)$ & $18(78 \%)$ & $9(82 \%)$ & / \\
\hline CRP, mg/L, normal range: $<1$ & $25(5,59)$ & $15(4,39)^{\& \Delta}$ & $77(30,103){ }^{\nabla}$ & $35(20,57)^{*}$ & $<0.001$ \\
\hline Increased & $87(81 \%)$ & $43(86 \%)$ & $18(78 \%)$ & 10(91\%) & / \\
\hline Serum ferritin, $\mu \mathrm{g} / \mathrm{L}$, normal range: $30-400$ & $497(234,975)$ & $376(182,709)^{\S \Delta}$ & $1202(513,1687)^{*}$ & $1023(534,1509)^{*}$ & 0.010 \\
\hline$\| \mathrm{L}-1 \beta, \mathrm{pg} / \mathrm{mL}$, normal range: $<5$ & $5(5,5)$ & $5(5,5)$ & $5(5,5.3)$ & $5(5,5)$ & 0.335 \\
\hline IL-2 receptor, U/mL, normal range: $223-710$ & $613(398,918)$ & $607(428,765)$ & $628(371,1079)$ & $1316(424,1653)$ & 0.445 \\
\hline IL-6, pg/mL, normal range: $<7$ & $11(3.6,31.9)$ & $4.5(3.2,16.2)$ & $29.3(15.1,60.3)$ & $11.7(5.5,79.1)$ & 0.103 \\
\hline IL-8, pg/mL, normal range: $<62$ & $12(7.6,25.8)$ & $10.3(6.9,26.2)$ & $14.7(8,24.8)$ & $9.4(5.4,43.2)$ & 0.947 \\
\hline IL-10, pg/mL, normal range: $<9.1$ & $5(5,5.3)$ & $5(5,5)$ & $5.5(5,9.5)$ & $5(5,10)$ & 0.188 \\
\hline TNF-a, pg/mL, normal range: $<8.1$ & $7.9(5.6,9.4)$ & $8.4(5.4,9.5)$ & $7.2(5.6,9.7)$ & $7.5(5,8.8)$ & 0.624 \\
\hline
\end{tabular}

Data are indicated as $\mathrm{n}(\%), \mathrm{n} / \mathrm{N}(\%)$, mean (SD), or median (IQR). Comparison of groups was determined using the Kruskall-Wallis test or the Mann-Whitney $\mathrm{U}$ test, as appropriate. IL, interleukin. TNF, tumor Necrosis Factor. ${ }^{*} P<0.01$ vs. group $1 ;{ }^{{ }^{5}} P<0.01$ vs. group $2 ;{ }^{\wedge} P<0.01$ vs. group $3 ;{ }^{\nabla} P<0.05$ vs. group $1 ;{ }^{8} P<0.05$ vs. group $2{ }^{f^{\prime}} P<0.05$ vs. group 3 
Table 3 Chest CT features of patients $(n=84)$

\begin{tabular}{ll}
\hline Chest radiographic feature & Patients, $\mathrm{n}(\%)$ or median (IQR) \\
\hline Frosted glass density & $38(45.2 \%)$ \\
Ground glass opacity & $45(53.6 \%)$ \\
Consolidation & $1(1.2 \%)$ \\
Radiographic score & $59(12,148)$ \\
Pleural effusions & $0(0 \%)$ \\
Anatomic sides involved & \\
Unilateral & $6(7.1 \%)$ \\
Bilateral & $78(92.9 \%)$ \\
Predominant distribution & \\
Central & $2(2.3 \%)$ \\
Peripheral & $1(1.2)$ \\
Central and peripheral & $81(96.4 \%)$ \\
Involved zone & \\
Suprasternal notch & $37(44.1 \%)$ \\
Aortic arch & $67(79.8 \%)$ \\
Tracheal carina & $77(91.7 \%)$ \\
Intermediate bronchus & $76(90.5 \%)$ \\
Apex of diaphragm & $79(94.1 \%)$ \\
\hline
\end{tabular}

Data are indicated as $n(\%), n / N(\%)$

\section{Chest CT features}

Chest CT images at admission were taken for 84 of 108 patients, and all CT images indicated abnormalities (Table 3). The typical findings were bilateral frosted glass density, ground-glass opacity (GGO), and consolidation (Fig. 1). Chest CT images showed that the diffuse density of both lungs increased, and the transparency of the lung field weakened. The lighter ones were frosted glass (Fig. 1a), with lower attenuation than the ground glass (Fig. 1b). GGO was present in 45 patients $(53.6 \%)$, followed by frosted glass density $(n=38,45.2 \%)$, and consolidation ( $n=1,0.93 \%)$. None of the patients had pleural effusion. Analysis of involved zones indicated that the base of the lung was most affected region (apex of diaphragm: $n=79,94.1 \%)$, most patients had central and peripheral distribution $(n=81,96.4 \%)$, and most patients had bilateral involvement $(n=78,92.9 \%)$.

\section{Chest CT scores}

We divided the patients into three subgroups based on the chest CT score (0 to 100, 101 to 200, and above 200), and then compared the characteristics of these subgroups (Table 2). Analysis of blood cell counts indicated that the WBC, neutrophil, and lymphocyte counts were significantly lower $(P \leq 0.001)$ in patients with higher CT scores. Patients in the three groups also had significant differences in D-dimer $(P<0.001)$, blood urea nitrogen (BUN, $P=0.022)$, lactate dehydrogenase $(P<0.001)$, troponin $(P=0.013)$, procalcitonin $(P<0.001)$, ESR $(P=0.002)$, CRP $(P<0.001)$, and serum ferritin $(P<0.010)$.

Comparison of the left and right lung layers indicated the right lung score was higher, but this was not statistically significant $(P>0.05)$ (Fig. $2 \mathrm{a})$. A comparison of CT scores of the two lungs at different areas indicated that the chest CT score significantly increased from the top to the bottom of the lungs (Fig. 2b).

\section{Association of chest CT score with inflammatory mediators}

Correlation analysis (Fig. 3) indicated that chest CT score had significantly positive correlations with WBC count

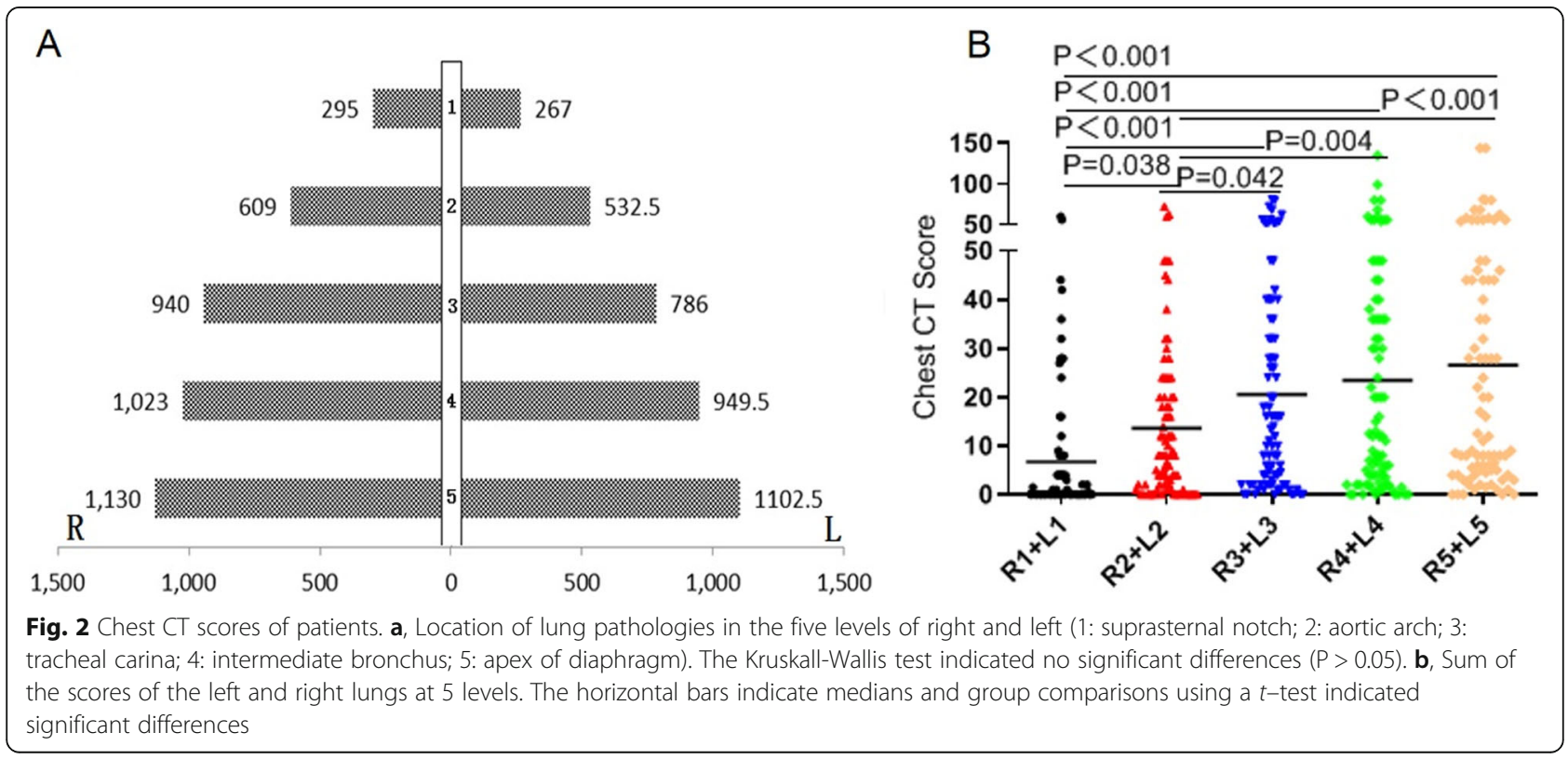




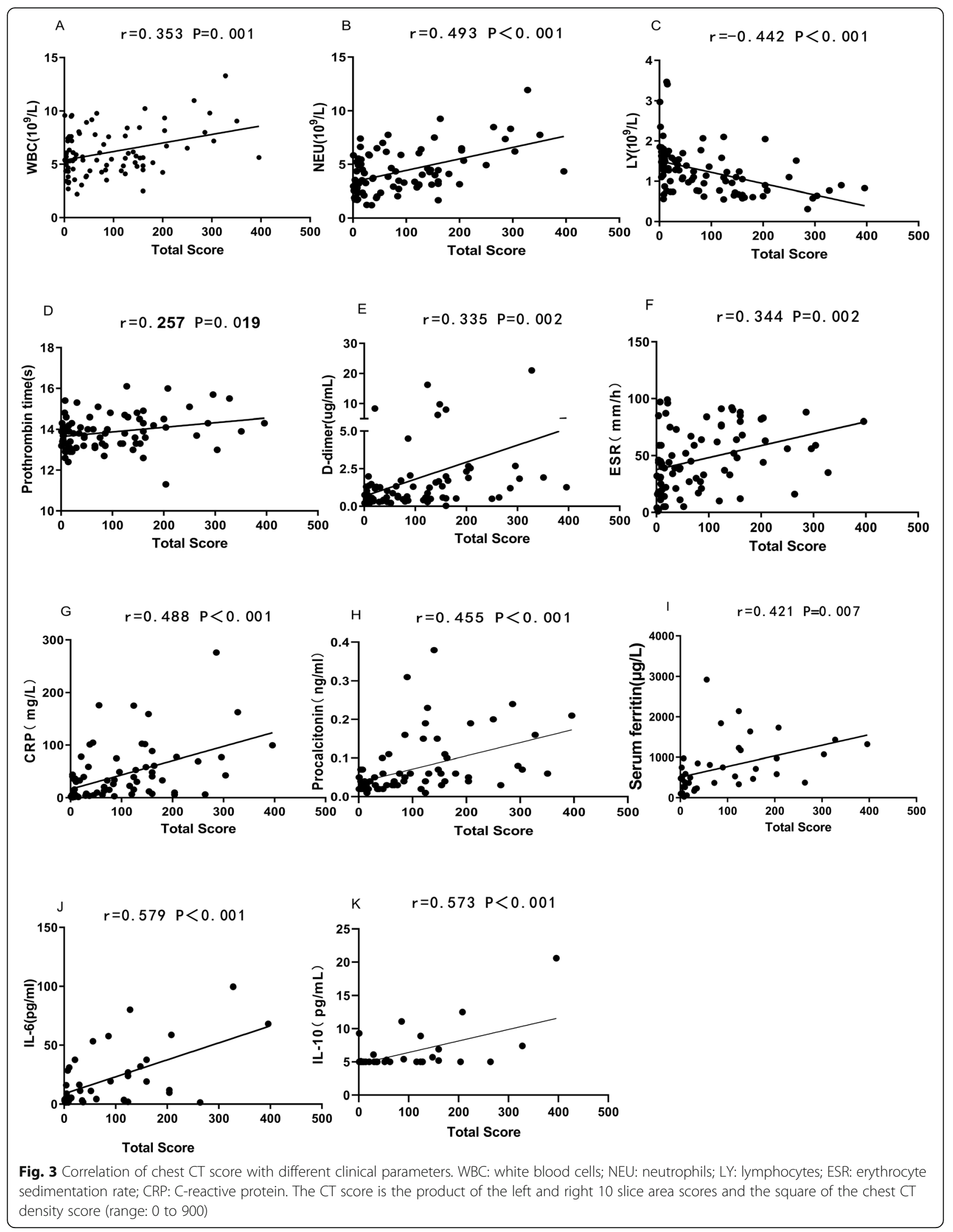




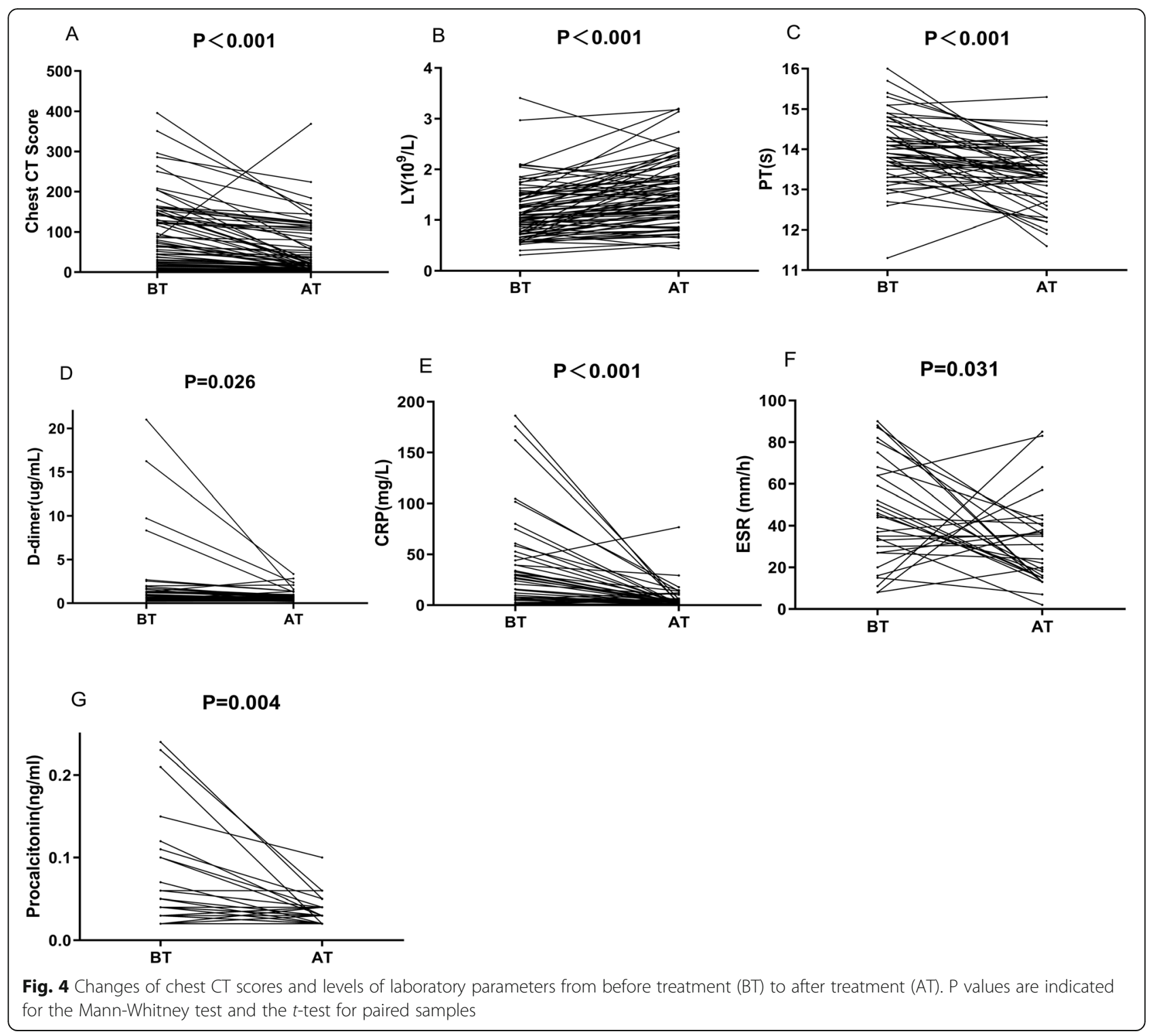

$(P=0.001)$, neutrophil count $(P<0.001)$; prothrombin time (PT, $P=0.019)$, the levels of D-dimer $(P=0.002)$, ESR $(P=$ $0.002)$, CRP $(P<0.001)$, procalcitonin $(P<0.001)$, serum ferritin $(P<0.007)$, IL-6 $(P<0.001)$, and IL-10 $(P<0.001)$; and a negative correlation with LY count $(P<0.001)$.

\section{Chest CT score and laboratory parameters before and after treatment}

After treatment, the chest CT score $(P<0.001)$, and the levels of ESR $(P=0.031)$, CRP $(P<0.001)$, and procalcitonin $(P=0.004)$ were significantly lower than before treatment, but the LY count $(P<0.001)$ was significantly greater (Fig. 4$)$.

\section{Association of glucocorticoid use with chest CT score and laboratory parameters}

We also divided patients into a glucocorticoid group $(n=24,22 \%)$ and a non-glucocorticoid group $(n=84$, $78 \%)$ and compared their laboratory parameters and chest CT scores after treatment (Fig. 5). The results indicated that glucocorticoid use had significant positive relationships with WBC count $(P<0.001)$ and LY count $(P<0.001)$ and significant negative relationships with the levels of activated partial thromboplastin time (APTT, $P=0.023)$, and PT $(P=0.013)$. Notably, the CT score declined more in users than non-users of a glucocorticoid $(P<0.001)$. 


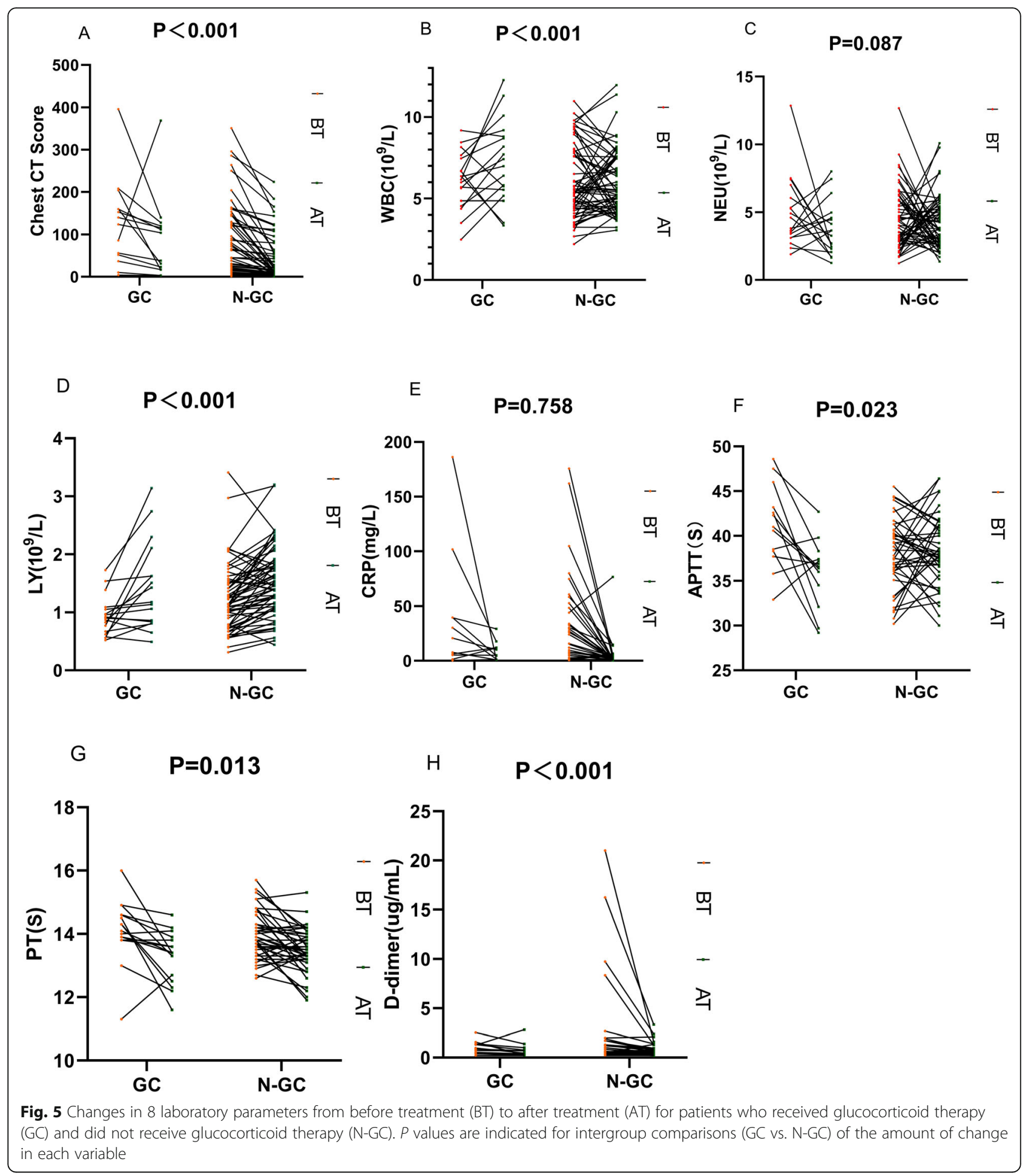

Correlations of changes in chest CT score with changes in other laboratory parameters

We further examined the correlation between the change in chest $\mathrm{CT}$ score from before to after treatment ( $\triangle \mathrm{CT}$ score) with changes in other laboratory parameters from before to after treatment (Table 4). The results indicated that $\triangle \mathrm{CT}$ score had a positive correlation with $\triangle \mathrm{LY}$ count $(P=0.048)$ and a negative correlation with $\triangle \mathrm{ESR}(P=0.027)$.

\section{Discussion}

This study indicated that patients who were hospitalized with COVID-19 tended to be older than those in the 
Table 4 Partial correlation analysis of change in chest CT score from before to after treatment ( $\Delta C T$ score) with changes in different laboratory parameters $(\Delta)$ from before to after treatment

\begin{tabular}{lll}
\hline Laboratory parameter & $r$ & $P$ \\
\hline$\Delta$ WBC count & 0.171 & 0.184 \\
$\Delta$ Neutrophil count & -0.057 & 0.682 \\
$\Delta$ LY count & $\mathbf{0 . 2 5 1}$ & $\mathbf{0 . 0 4 8}$ \\
$\Delta$ ESR & $-\mathbf{0 . 4 5 1}$ & $\mathbf{0 . 0 2 7}$ \\
$\Delta$ CRP & 0.029 & 0.868 \\
$\Delta$ Procalcitonin & 0.204 & 0.288 \\
$\Delta$ D-dimer & -0.068 & 0.679 \\
$\Delta$ PT & 0.092 & 0.544 \\
$\Delta$ APTT & 0.034 & 0.827 \\
\hline WBC white blood cell, LY lymphocyte, ESR erythrocyte sedimentation rate, CRP \\
C-reactive protein, $P T$ prothrombin time, APTT activated partial \\
thromboplastin time &
\end{tabular}

general population. Among all patients, $68 \%$ had one or more coexisting medical conditions, such as hypertension, cardiac disease, or chronic obstructive pulmonary disease. Our finding that COVID-19 is more common in older adults with coexisting chronic diseases is consistent with previous publications $[11,16,17]$. Indeed, elderly men with underlying diseases appear to have the highest risk for development of COVID-19 [18]. The most common symptoms at the onset of illness were fever, dry cough, myalgia, fatigue, dyspnea, and anorexia. The lung CT scans indicated that the most common manifestations were bilateral distribution of patchy shadows and ground glass opacity without pleural effusion. The lung CT results also indicated that the most severely affected patients were older.

Our analysis of laboratory data indicated the LY count was reduced in most patients, and that a greater chest CT score negatively correlated with LY count. This suggests that COVID-19 might act directly upon LYs, especially TLYs, as previously reported for SARS-CoV and MERS-CoV $[19,20]$. Recent studies found that the severity of lymphopenia correlated with the severity of COVID-19 [21]. Our results indicated that the chest CT score had a positive correlation with the extent of lymphopenia. In agreement, a previous study reported that the semi-quantitative non-invasive chest $\mathrm{CT}$ score reliably predicted COVID-19 prognosis. As viruses spread through the respiratory mucosa and infect other cells, they induce a cytokine storm and a series of immune responses that cause changes in peripheral WBCs and immune cells. Coronviruses invade the lungs, as well as the blood, digestive system, and circulatory system [22-24]. Our analysis indicated that high chest CT score had a positive correlation with abnormal blood coagulation (based on measurements of PT and D-dimer), and severe cases are prone to fibrinolytic activation and excessive bleeding. This is consistent with the findings of Chen et al. [11]. Zhang et al. [25] found coagulation dysfunction and antiphospholipid antibodies in 3 patients with COVID-19; Antiphospholipid antibodies can occur in patients with infectious diseases, and function in the exogenous coagulation pathway. Combined with our research, which indicated no significant relationship of APTT level with chest CT score, we suggest that SARS$\mathrm{CoV}-2$ may mainly affect the exogenous coagulation pathway.

Our analysis of chest CT scores of patients with COVID-19 indicated that the lesions were mainly at level 5, suggesting that the virus is most abundant in the more active parts of the lung. We also found that the initial chest CT score was positively correlated with the levels of systemic inflammatory factors (CRP and ESR). The overall radiologic score is based on the severity of air-space disease and its distribution. Previous studies found that patients who had viral pneumonias with consolidations evident in lung CT had more severe clinical courses than those who presented with ground glass opacities [26, 27]. These abnormalities also correlated with diffuse alveolar damage [28]. Patients who have COVID-19 and bilateral consolidations tended to have severe systemic inflammation. Because COVID-19 is an extremely contagious and potentially fatal disease, risk stratification using the simple chest $\mathrm{CT}$ scoring that we used here may help to appropriately triage patients, so that patients with more severe disease can receive more aggressive treatment and closer monitoring. In other words, the chest $\mathrm{CT}$ score should be considered for risk stratification of patients with COVID-19. However, use of initial chest CT scores for prediction of clinical outcome of patients with COVID-19 requires confirmation.

Further genetic, clinical, epidemiological, and clinical studies are needed to examine the efficacy of this semi-quantitative chest $\mathrm{CT}$ grading system to predict outcome, evaluate disease phenotypes, monitor disease progression, and evaluate treatment response and efficacy for other forms of viral pneumonia or air space diseases.

Due to the serious adverse effects of glucocorticoids experienced by patients with SARS-CoV infections $[29,30]$, it is questionable whether glucocorticoids should be used to treat patients with SARS-CoV-2 infections [31, 32]. Our results showed that patients who received glucocorticoids had greater improvements of chest CT score and LY count. This suggests that moderate application of glucocorticoids may have a positive effect in these patients. Our regression analysis indicated that the change of chest CT score after treatment had a positive correlation with the change in LY count, indicating that the chest CT score is useful in assessing patient status before and after treatment. 
There were several limitations in this study. First, this was retrospective study and included only relatively small number of cases. All patients were reported to the CDC from January 2020 to February 202,020 and required hospitalization, but were not admitted to the ICU. Therefore, the analysis was biased toward patients with more severe forms of COVID-19. However, the patients we examined were from the general ward, and none were admitted to the ICU. Therefore, many patients with COVID-19 have higher chest CT scores. Second, because we only examined five levels in the chest CT examinations, we may have missed some lesions. Last, because of time constraints, we only performed a cross-sectional study, and did not perform follow-up CT scans. All chest CT images were from patients at the time of admission and prior to treatment.

Some of the patients we examined progressed rapidly to ARDS, septic shock, and then multiple organ failure. Therefore, early identification and timely treatment of these critical cases is of crucial importance. The chest CT score is a non-invasive method that provides an actionable means for achieving this goal.

\section{Conclusions}

In conclusion, the chest CT score of patients with COVID-19 is associated the severity of the systemic inflammatory response. The damage from SARS-CoV-2 infection is greater in more active parts of the lung. Because COVID-19 is potentially fatal and highly contagious, risk stratification based on air-space disease may help to triage patients, guide treatment, and monitor disease progression and treatment.

\section{Supplementary information}

Supplementary information accompanies this paper at https://doi.org/10. 1186/s12931-020-01440-x.

Additional file 1: Figure S1. A, suprasternal notch; B, aortic arch; C, tracheal carina; D, intermediate bronchus; E, apex of diaphragm.

\section{Abbreviations}

CT: Computed tomography; CRP: C-reactive protein; ESR: Erythrocyte sedimentation rate; LY: Lymphocyte; WBC: White blood cell; SARS: Severe acute respiratory syndrome; ARDS: Acute respiratory distress syndrome; MERS: Middle East respiratory syndrome; CK-MB: Creatine kinase-MB; GGO: Ground-glass opacity; NEU: Neutrophil; PT: Prothrombin time; APTT: Activated partial thromboplastin time

\section{Acknowledgements}

Not applicable.

\section{Authors' contributions}

$J Z, G M$ and WL carried out the data collection, literature review and drafting of the manuscript. BS, HD contributed to the drafting of the manuscript and aided in the literature review. ZS, and QH participated in the data collection and the drafting of the manuscript. PG help to draft the manuscript and revised the final version of the manuscript. All authors read and approved the final manuscript.
Funding

Not applicable.

Availability of data and materials

All data generated or analyzed during this study are included in this published article.

Ethics approval and consent to participate

Ethics Committee of the Second Hospital of Jilin University approved this study.

Consent for publication

Oral consent to publish was obtained from all patients in this study.

\section{Competing interests}

All authors have read and approved the content, and declare no conflicts of interest. There is no ethical/legal conflicts involved in the article.

\section{Author details}

'Department of Respiratory and Critical Care Medicine, The Second Hospital of Jilin University, Changchun, Jilin, China. ${ }^{2}$ Department of Radiology, The Second Hospital of Jilin University, Changchun, Jilin, China.

Received: 31 March 2020 Accepted: 3 July 2020

Published online: 14 July 2020

References

1. Wuhan Municipal Health Commission. Report of clustering pneumonia of unknown etiology in Wuhan City. 2019. Accessed 23 Feb 2020 [http://wjw. wuhan.gov.cn/front/web/showDetail/2019123108989].

2. Lu H, Stratton CW, Tang YW. Outbreak of pneumonia of unknown etiology in Wuhan, China: the mystery and the miracle. J Med Virol. 2020;92:401-2.

3. National Health Commission of the People's Republic of China. Report Aggregated pneumonia of unknown etiology China. 2020. [http://www.nhc. gov.cn/xcs/yqtb/202003/114113d25c1d47aabe68381e836f06a8.shtml].

4. WHO. Novel coronavirus (2019-nCoV). 2020. [https://www.who.int/ emergencies/diseases/novel-coronavirus-2019/situation-reports].

5. Hui DS, Azhar El, Madani TA, Ntoumi F, Kock R, Dar O, Ippolito G, McHugh TD, Memish ZA, Drosten C, et al. The continuing 2019-nCoV epidemic threat of novel coronaviruses to global health - the latest 2019 novel coronavirus outbreak in Wuhan, China. Int J Infect Dis. 2020;91:264-6.

6. Z Zhu N, Zhang D, Wang W, Li X, Yang B, Song J, Zhao X, Huang B, Shi W, Lu $\mathrm{R}$, et al. A novel coronavirus from patients with pneumonia in China, 2019. N Engl J Med. 2020;382:727-33.

7. Huang C, Wang Y, Li X, Ren L, Zhao J, Hu Y, Zhang L, Fan G, Xu J, Gu X, et al. Clinical features of patients infected with 2019 novel coronavirus in Wuhan, China. Lancet. 2020;395:497-506.

8. WHO. Clinical management of severe acute respiratory infection when Novel coronavirus (nCoV) infection is suspected: interim guidance. 2020. [https://www.who.int/internal-publications-detail/clinical-management-ofsevere-acute-respiratory-infection-when-novel-coronavirus-(ncov)-infectionis-suspected].

9. Yin Y, Wunderink RG. MERS, SARS and other coronaviruses as causes of pneumonia. Respirology. 2018;23:130-7

10. Cui J, Li F, Shi ZL. Origin and evolution of pathogenic coronaviruses. Nat Rev Microbiol. 2019;17:181-92.

11. Chen N, Zhou M, Dong X, Qu J, Gong F, Han Y, Qiu Y, Wang J, Liu Y, Wei Y, et al. Epidemiological and clinical characteristics of 99 cases of 2019 novel coronavirus pneumonia in Wuhan, China: a descriptive study. Lancet. 2020; 395:507-13

12. Pediatric Branch of Hubei Medical A, Pediatric Branch of Wuhan Medical A, Pediatric Medical Quality Control Center of H. Recommendation for the diagnosis and treatment of novel coronavirus infection in children in Hubei (Trial version 1). Zhongguo Dang Dai Er Ke Za Zhi. 2020;22:96-9.

13. Pan Y, Guan H, Zhou S, Wang Y, Li Q, Zhu T, Hu Q, Xia L. Initial CT findings and temporal changes in patients with the novel coronavirus pneumonia (2019-nCoV): a study of 63 patients in Wuhan. Eur Radiol: China; 2020.

14. National Health Commission of the People's Republic of China, Diagnosis and Treatment of Pneumonia Caused by New Coronavirus (Trial Version 4). 2020. [http://www.nhc.gov.cn/yzygj/s7653p/202001/4294563ed35b43209b31 739bd0785e67.shtml]. 
15. Feng F, Jiang Y, Yuan M, Shen J, Yin H, Geng D, Xu J, Hua Y, Shi J, Shi Y, Zhang Z. Association of radiologic findings with mortality in patients with avian influenza H7N9 pneumonia. PLoS One. 2014;9:e93885.

16. Wang D, Hu B, Hu C, Zhu F, Liu X, Zhang J, Wang B, Xiang H, Cheng Z, Xiong Y, et al. Clinical characteristics of 138 hospitalized patients with 2019 novel coronavirus-infected pneumonia in Wuhan, China. JAMA. 2020; 323(11):1061-9.

17. Kui L, Fang YY, Deng Y, Liu W, Wang MF, Ma JP, Xiao W, Wang YN, Zhong $\mathrm{MH}, \mathrm{Li} \mathrm{CH}$, et al. Clinical characteristics of novel coronavirus cases in tertiary hospitals in Hubei Province. Chin Med J. 2020;133(9):1025-31.

18. Special Expert Group for Control of the Epidemic of Novel Coronavirus Pneumonia of the Chinese Preventive Medicine A. An update on the epidemiological characteristics of novel coronavirus pneumoniaCOVID-19. Zhonghua Liu Xing Bing Xue Za Zhi. 2020;41:139-44.

19. Channappanavar R, Zhao J, Perlman S. T cell-mediated immune response to respiratory coronaviruses. Immunol Res. 2014;59:118-28.

20. Chu H, Zhou J, Wong BH, Li C, Chan JF, Cheng ZS, Yang D, Wang D, Lee $A C$, Li C, et al. Middle East respiratory syndrome coronavirus efficiently infects human primary T lymphocytes and activates the extrinsic and intrinsic apoptosis pathways. J Infect Dis. 2016;213:904-14.

21. Yang X, Yu Y, Xu J, Shu H, Xia J, Liu H, Wu Y, Zhang L, Yu Z, Fang M, et al. Clinical course and outcomes of critically ill patients with SARS-CoV-2 pneumonia in Wuhan, China: a single-centered, retrospective, observational study. Lancet Respir Med. 2020;8(5):475-81.

22. Gambotto A, Barratt-Boyes SM, de Jong MD, Neumann G, Kawaoka Y. Human infection with highly pathogenic H5N1 influenza virus. Lancet. 2008; 371:1464-75.

23. Lau SK, Lau CC, Chan KH, Li CP, Chen H, Jin DY, Chan JF, Woo PC, Yuen KY. Delayed induction of proinflammatory cytokines and suppression of innate antiviral response by the novel Middle East respiratory syndrome coronavirus: implications for pathogenesis and treatment. J Gen Virol. 2013; 94:2679-90.

24. Wauquier N, Becquart P, Padilla C, Baize S, Leroy EM. Human fatal Zaire ebola virus infection is associated with an aberrant innate immunity and with massive lymphocyte apoptosis. PLoS Negl Trop Dis. 2010;4:e837.

25. Zhang Y, Xiao M, Zhang S, Xia P, Cao W, Jiang W, Chen H, Ding X, Zhao H, Zhang $\mathrm{H}$, et al. Coagulopathy and Antiphospholipid antibodies in patients with Covid-19. N Engl J Med. 2020;382:e38.

26. Grinblat L, Shulman H, Glickman A, Matukas L, Paul N. Severe acute respiratory syndrome: radiographic review of 40 probable cases in Toronto, Canada. Radiology. 2003;228:802-9.

27. Gattinoni L, Caironi P, Cressoni M, Chiumello D, Ranieri VM, Quintel M, Russo S, Patroniti N, Cornejo R, Bugedo G. Lung recruitment in patients with the acute respiratory distress syndrome. N Engl J Med. 2006;354:1775-86.

28. Marchiori E, Zanetti G, Fontes CA, Santos ML, Valiante PM, Mano CM, Teixeira GH, Hochhegger B. Influenza a (H1N1) virus-associated pneumonia: high-resolution computed tomography-pathologic correlation. Eur J Radiol. 2011;80:e500-4.

29. Li N, Wang GF, Wu YF, Xie GQ, Xiao F, Chen BW, Wang YX. Han DM: [side effects of glucocorticosteroids in the management of 1291 patients of SARS]. Beijing Da Xue Xue Bao. 2004;36:519-24.

30. Zhao R, Wang H, Wang $X$, Feng F. Steroid therapy and the risk of osteonecrosis in SARS patients: a dose-response meta-analysis. Osteoporos Int. 2017;28:1027-34

31. Xu K, Cai H, Shen Y, Ni Q, Chen Y, Hu S, Li J, Wang H, Yu L, Huang H, et al. Management of corona virus disease-19 (COVID-19): the Zhejiang experience. Zhejiang Da Xue Xue Bao Yi Xue Ban. 2020;49:0.

32. Ling $Y, X u S B$, Lin $Y X$, Tian $D$, Zhu ZQ, Dai FH, Wu F, Song ZG, Huang $W$, Chen J, et al. Persistence and clearance of viral RNA in 2019 novel coronavirus disease rehabilitation patients. Chin Med J. 2020;133(9):1039-43.

\section{Publisher's Note}

Springer Nature remains neutral with regard to jurisdictional claims in published maps and institutional affiliations.

\section{Ready to submit your research? Choose BMC and benefit from:}

- fast, convenient online submission

- thorough peer review by experienced researchers in your field

- rapid publication on acceptance

- support for research data, including large and complex data types

- gold Open Access which fosters wider collaboration and increased citations

- maximum visibility for your research: over $100 \mathrm{M}$ website views per year

At BMC, research is always in progress.

Learn more biomedcentral.com/submissions 